\title{
TINGKAT PENGETAHUAN SISWI SMA IMUHAMMMADYAH PALANGKA RAYA TENTANG DYSMENORRHEA
}

\section{Level of Knowledge of Female Students in Muhammadiyah Senior High School of Palangka Raya about Dysmenorrhea}

\author{
Syahrida Dian Ardhany \\ Department of Pharmacy, Faculty of Health Science, Universitas Muhammadiyah Palangkaraya, RTA. Milono St. Km. I.5 Palangka Raya, \\ Indonesia \\ *e-mail : chass50I@gmail.com
}

\begin{abstract}
ABSTRAK
Dismenore merupakan salah satu masalah ginekologi yang paling umum di alami wanita dari berbagai tingkat usia, angka kejadian dismenore di dunia sangat besar rata-rata lebih dari 50\% wanita di setiap dunia mengalaminya. SMA Muhammadiyah Palangka Raya merupakan salah satu sekolah terbaik di Kota Palangka Raya. Berdasarkan observasi yang telah dilakukan peneliti hasil yang didapat ialah banyak siswi yang mengalami dysmenorrhea dengan nyeri yang hebat dan tentu saja kondisi ini akan mengganggu aktivitas sehari-hari terutama saat kegiatan proses belajar mengajar juga kegiatan ekstrakurikuler sehingga perlu dilakukan penelitian tentang tingkat pengetahuan disminore. Metode penelitian yang digunakan dalam penelitian ini adalah metode deskriptif dengan tekhnik pengambilan sampel purposive sampling menggunakan kuisoner dengan 10 item pernyataan dengan 4 indikator yaitu pengertian dysmenorrhea, tanda dan gejala dysmenorrhea, penyebab dysmenorrhea, dan cara penanganan dan pencegahan dysmenorrhea. Berdasarkan hasil penelitian didapatkan bahwa secara keseluruhan tingkat pengetahuan siswi SMA Muhammadiyah Palangka Raya termasuk dalam kategori cukup mengetahui dengan persentase $66,67 \%$, sedangkan berdasarkan indikator tingkat pengetahuan pengertian tentang dysmenorrhea 73,22\% (kategori cukup mengetahui), 58,93\% (kategori cukup mengetahui) untuk indikator tanda dan gejala dysmenorrhea, 63,69\% (kategori cukup mengetahui) untuk indikator penyebab dysmenorrhea dan 68,75\% (kategori cukup mengetahui) untuk indikator cara penanganan dan pencegahan dysmenorrhea. Berdasarkan hasil penelitian maka dapat disimpulkan tingkat pengetahuan siswi SMA Muhammadiyah Palangka Raya tentang dysmenorrhea termasuk dalam kategori cukup mengetahui dengan persentase $66,67 \%$
\end{abstract}

Kata kunci: Dysmenorrhea, siswi, tingkat pengetahuan

\begin{abstract}
Dysmenorrhea is one of the most common gynecological problems in women of all ages, the incidence of dysmenorrhea in the world is very large on average more than $50 \%$ of women in every world experience it. Muhammadiyah Senior High School is one of the best schools in Palangka Raya. Based on the observations that have been done by researcher the results are many students got dysmenorrhea with severe pain and certainly this condition will disrupt daily activity, especially when teaching and learning and so extracurricular activities. Therefore, research about level of dysmenorrhea knowledge is needed. The research method was used in this research was descriptive method with technique of sampling purposive sampling with 10 statements questionnaire consist of 4 indicators there are definition of dysmenorrhea, signs and symptoms of dysmenorrhea, causes of dysmenorrhea and how to treat and prevent dysmenorrhea. Based on the results of the study was found that the level of dysmenorrhea knowledge female students Muhammadiyah Senior High School of Palangka Raya included in the sufficient category with percentage $66,67 \%$, meanwhile based on knowledge indicators, definition of dysmenorrhea was $73.22 \%$ (sufficient category), signs and symptoms of dysmenorrhea was $58.93 \%$ (sufficient category), causes of dysmenorrhea was $63.69 \%$ (sufficient category) and how to treat and prevent dysmenorrhea was $68.75 \%$ (sufficient category). Based on the results of this study, it can be concluded that the level of dysmenorrhea knowledge female students Muhammadiyah Senior High School of Palangka Raya included in category sufficient to know with percentage $66.67 \%$.
\end{abstract}

Keywords: Dysmenorrhea, female student, level of knowledge

\section{PENDAHULUAN}

Remaja merupakan suatu masa kehidupan individu dimana terjadi perkembangan psikologis untuk menemukan jati diri atau identidas diri. Masa remaja merupakan masa peralihan dari masa kanak-kanak menuju masa dewasa, dimana pada masa itu terjadi pertumbuhan yang pesat termasuk fungsi reproduksi sehingga mempengaruhi terjadinya perubahan perkembangan-perkembangan fisik, mental maupun sosial (Proverawati \& Siti, 2009). Masa remaja (usia 10I9 tahun) merupakan masa yang khusus dan penting karena merupakan periode pematangan organ reproduksi manusia dan sering disebut masa pubertas. Pada remaja wanita sebagai tanda kematangan organ reproduksi adalah ditandai dengan datangnya menstruasi (Kumalasari dalam Anugraeni, 2017). Pada saat menstruasi, wanita 
kadang mengalami nyeri. Sifat dan tingkat rasa nyeri bervariasi, mulai dari yang ringan hingga yang berat. Kondisi tersebut dinamakan dismenorea, yaitu keadaan nyeri yang hebat dan dapat mengganggu aktivitas seharihari (Kusmiran dalam Anugraeni, 2017).

Angka kejadian dismenorea di dunia sangat besar. Ratarata lebih dari $50 \%$ perempuan di setiap dunia mengalaminya. Dari hasil penelitian, di Amerika persentase kejadian dismenorea sekitar $60 \%$, Swedia $72 \%$ dan di Indonesia 55\% (Abidin, 2014). Di Indonesia diperkirakan $55 \%$ perempuan usia produktif tersiksa oleh nyeri haid sedangkan angka kejadian nyeri haid berkisar 45-95\% dikalangan wanita usia produktif (Helvina, 20I6).

Nyeri haid yang banyak dialami oleh remaja putri juga menjadi salah satu penyebab utama ketidakhadiran di sekolah. Selain menurunkan angka kehadiran $69,7 \%$ remaja putri yang mengalami dismenorea juga mengaku mengalami penurunan dalam prestasi akademik, penurunan konsentrasi $(72,7 \%)$ dan ketidakmampuan untuk menjawab pertanyaan dalam ujian $(54,3 \%)$. Lebih dari $60 \%$ responden mengaku hubungan sosialisasinya terganggu jarena dismenorea (Rakhshaee, 2014).

Pengetahuan remaja putri mengenai dismenorea masih belum cukup baik sehingga banyak remaja putri yang tidak mengetahui bagaimana cara penanganan dismenorea yang benar. Berdasarkan penelitian yang dilakukan di Demak diketahui $78,3 \%$ siswi memiliki pengetahuan yang kurang tentang dismenorea, hanya $4,3 \%$ siswi yang memiliki pengetahuan yang baik mengenai dismenorea (Nafiroh dan Indrawati, 2013). Kurangnya tingkat pengetahuan mengenai kesehatan reproduksi dapat dikrenakan kurangnya sumber informasi. Pengetahuan mengenai kesehatan reproduksi yang diberikan di sekolah hanya didapatkan melalui mata pelajaran biologi. Materi yang diajarkan hanya mengajarkan anatomi hewan, tumbuhan dan susunan anatomi organ reproduksi beserta manfaatnya, tidak membahas permasalahan yang menyertai sistem reproduki (Nafiroh \& Indrawati, 20I3).

SMA Muhammadiyah Palangka Raya merupakan salah satu sekolah terbaik di Kota Palangka Raya. Siswa dan siswi yang dapat masuk di sekolah tersebut merupakan hasil dari seleksi akademis dan juga agamis. Berdasarkan observasi yang telah dilakukan peneliti hasil yang didapat ialah banyak siswi yang mengalami dysmenorrhea yang beristirahat di Usaha Kesehatan Sekolah dalam setiap minggunya dan bahkan pernah terdapat siswi yang mengalami pingsan karena hal tersebut. Kejadian dysmenorrhea tentu saja akan mengganggu aktivitas kegiatan sekolah termasuk proses belajar dan mengajar. Atas dasar hal tersebut maka peneliti tertarik untuk menjadikan siswi SMA Muhammadiyah Palangka Raya sebagai objek penelitian karena begitu pentingnya pengetahuan yang berkaitan dengan kesehatan reproduksi pada masa remaja.

\section{METODOLOGI}

\section{Metode Penelitian}

Metode penelitian ini adalah metode deskriptif. Populasi dalam penelitian ini adalah siswi SMA Muhammadiyah Palangka Raya kelas X dan XI dengan jumlah 121 siswi, kemudian dihitung menggunakan slovin didapatkan angka minimal sampel/responden 55 siswi, namun jumlah sampel yang terambil adalah 84 siswi/responden.

Teknik yang digunakan untuk mengumpulkan data-data adalah angket/kuesioner dengan tekhnik pengambilan sample purposive sampling yaitu dengan kriteria inklusi siswi yang telah menstruasi. Dalam penelitian ini kuesioner berisi 10 pernyataan yang dijawab langsung oleh responden tanpa diwakilkan oleh orang lain. Responden memberikan jawaban atas pernyataan yang diajukan oleh peneliti dengan pilihan jawaban "Benar" dan "Salah", dengan skor penilaian $y a=1$, tidak $=0$.

\section{Analisis Data}

Teknik analisis data yang digunakan dalam penelitian ini berdasarkan rumus persentase dan kriteria penilaian. Kriteria penilaian menurut Sibaragiang et al (2010) pengukuran pengetahuan responden didasarkan pada jawaban responden dari semua pernyataan yang diberikan, pengetahuan baik apabila nilai $>75 \%$, cukup apabila nilai $40-75 \%$ dan kurang apabila nilai $<40 \%$.

\section{HASIL DAN PEMBAHASAN}

Penelitian tentang dysmenorrhea ini dilakukan di SMA Muhammadiyah Palangka Raya. Metode penelitian yang digunakan adalah deskriptif dengan menggunakan kuisioner berisi 10 item pernyataan tentang tingkat pengetahuan siswi terhadap dysmenorrhea. Sampel atau responden yang digunakan pada penelitian ini adalah siswi kelas $\mathrm{X}$ dan kelas $\mathrm{XI}$ saja karena kelas XII fokus terhadap ujian nasional. Jumlah responden dihitung berdasarkan rumus slovin, taraf kepercayaan yang digunakan dalam penelitian ini awalnya adalah $5 \%$ namun karena terkendala libur panjang bulan Ramadhan sampel yang diharapkan tidak memenuhi, sehingga menggunakan taraf kepercayaan 10\% didapatkan jumlah responden sebanyak 84 responden/siswi. Teknik pengambilan sampel menggunakan purposive sampling berdasarkan kriteria tertentu salah satunya siswi yang telah menstruasi. 
Kuisioner berisi 10 item pernyataan yang memuat 4 indikator, yaitu indikator pengetahuan secara umum dysmenorrhea atau pengertiannya, tanda dan gejala dysmenorrhea, penyebab dysmenorrhea, dan cara penanganan dan pencegahan dysmenorrhea. Tekhnik analisa data yang digunakan adalah rumus persentase dengan kriteria penilaian berdasarkan kunci jawaban 10 item pernyataan yang benar.

Berdasarkan hasil penelitian untuk indikator pertama yaitu pengertian dysmenorrhea dengan no item pernyataan I dan 2 didapatkan responden yang menjawab benar sesuai kunci jawaban adalah $90,48 \%$ untuk no item pernyataan I dan 55,95\% untuk no item pernyataan 2, dengan hasil rata-rata $73,22 \%$, termasuk dalam kategori cukup mengetahui (Tabel I). Pada item pernyataan no item I hampir seluruh siswi mengetahui definisi dysmenorrhea, hal ini dimungkinkan karena para siswi telah diberi pengetahuan atau pelajaran tentang kesehatan reproduksi sejak dini dan di era serba digital ini juga membuat siswi lebih mudah untuk mendapatkan informasi tentang dysmenorrhea. Dysmenorrhea atau disminore dalam bahasa Indonesia berarti nyeri pada saat menstruasi. Hampir semua wanita mengalami rasa tidak enak pada perut bagian bawah saat menstruasi. Namun, istilah disminore hanya dipakai bila nyeri begitu hebat sehingga mengganggu aktivitas dan memerlukan obatobatan (Sukarni \& Magareth, 2013; Rahmawati, 2016). Pada item pernyataan no item 2 sebagian ada yang menyatakan bahwa dysmenorrhea harus ditangani oleh dokter, dysmenorrhea tidak harus ditangani langsung oleh dokter namun bisa diberikan terapi farmakologis atau pun non farmakologis, terkecuali untuk nyeri yang tidak tertahankan dapat langsung ditangani oleh dokter. Indikator kedua yaitu tentang tanda dan gejala dysmenorrhea dengan no item pernyataan 3 dan 4 didapatkan responden yang menjawab benar sesuai kunci jawaban adalah 95,24\% untuk no item pernyataan 3 dan $22,62 \%$ untuk no item pernyataan 4 , dengan hasil ratarata 58,93\% termasuk kategori cukup mengetahui (Tabel II). Tanda dan gejala yang tercantum dalam kuisioner merupakan tanda dan gejala secara umum, namun yang di alami siswi bisa saja berbeda dari yang telah dicantumkan dalam kuisioner seperti mudah emosi, nyeri pada bagian payudara, susah tidur karena nyeri dan mudah lelah. Menurut Laila (20II) gejala-gejala fisik nyeri menstruasi adalah sakit perut, sakit kepala, mual, payudara bengkak, nyeri otot dan punggung serta pembengkakan di tungkai kaki. Beberapa wanita mengalami mual dan muntah, sakit kepala, letih, pingsan dan diare serta kelabilan emosi selama menstruasi (Reeder \& Koniak, 20I3).
Indikator ketiga membahas tentang penyebab dysminorrhea dengan no item pernyataan 5 dan 6 didapatkan responden yang menjawab benar sesuai kunci jawaban adalah 54,76\% untuk no item pernyataan 5 dan $72,62 \%$ untuk no item pernyataan 6 , dengan hasil ratarata $63,69 \%$ termasuk kategori cukup mengetahui (Tabel III) Pemicu penyebab disminore cukup banyak, menurut Yanti (20II) penyebab terjadinya dysminorrhea primer yaitu dari faktor psikologis biasanya terjadi pada remaja dengan emosi yang tidak stabil, faktor endokrin yang dihubungkan dengan kontraksi usus dan peningkatan produksi prostglandin yang akan menyebabkan terjadinya kontraksi uterus yang tidak terkoordinasi, sedangkan penyebab terjadinya dysminorrhea sekunder yaitu faktor konstitusi seperti anemia, benjolan yang menyebabkan perdarahan, tumor atau fibroid, anomali uterus konginental seperti rahim yang terbalik dan peradangan selaput lendir rahim dan endometriosis. Selain itu, menurut Diyan (2013) penyebab terjadinya dismenore yaitu keadaan psikis dan fisik seperti stres, shock, penyempitan pembuluh darah, penyakit menahun, kurang darah dan kondisi tubuh yang menurun.

Indikator keempat yaitu tentang cara penanganan dan pencegahan dysminorrhea dengan no item pernyataan 7 sampai dengan 10 didapatkan responden yang menjawab benar sesuai kunci jawaban adalah $82,14 \%$ untuk no item pernyataan 7, 63,10\% untuk no item pernyataan 8, $77,38 \%$ untuk no item pernyataan 9 dan $52,38 \%$ untuk no item pernyataan 10 dengan hasil rata-rata $68,75 \%$ termasuk dalam kategori cukup mengetahui (Tabel IV). Menurut Anurogo dalam Yunitasari (2017), cara pencegahan dysminorhea adalah dengan cara menghindari stress, mengatur pola makan, menghindari makanan yang terlalu pedas dan asam, istirahat yang cukup, menghindari olahraga yang terlalu berat, menghindari mengkonsumsi minuman beralkohol, kopi, soda maupun coklat. Sedangkan menurut Laila (20II) untuk pengobatan dysminorrhea dapat dilakukan dengan cara mengkonsumsi obat analgesik, melakukan terapi hormonal, mengkonsumsi obat non steroid anti prostaglandin, mengompres dengan suhu yang panas, berolahraga dengan teratur dan melakukan pemijatan. Menurut Coco (1999) dalam Risnomarta et al (2015) pengobatan lini pertama yang paling tepat untuk disminore primer adalah OAINS (obat anti inflamasi non steroid) seperti parasetamol, asam mefenamat, dll. Selain itu, Zhang dan Li wan dalam Risnomarta et al (2015) menyebutkan 4 jenis OAINS yang efektif untuk mengobati disminore primer, yaitu Naproksen, Ibuprofen, asam mefenamat dan aspirin. 
Tabel I. Persentase Kuisioner Berdasarkan Indikator Pengertian Dysmenorrhea

\begin{tabular}{|c|c|c|c|c|}
\hline \multirow{2}{*}{ No. } & \multirow{2}{*}{ Pernyataan } & \multicolumn{2}{|c|}{ Jawaban berdasarkan Kunci $(n=84)$} & \multirow{2}{*}{$\begin{array}{c}\text { Persentase } \\
\text { Jawaban Benar (\%) }\end{array}$} \\
\hline & & Benar & Salah & \\
\hline 1 & $\begin{array}{l}\text { Dysmenorrhea merupakan rasa nyeri yang timbul ketika } \\
\text { menstruasi. }\end{array}$ & 76 & 8 & 90,48 \\
\hline 2 & Dysmenorrhea harus ditangani oleh dokter & 47 & 8 & 55,95 \\
\hline \multicolumn{4}{|c|}{ Rata-rata persentase } & 73,22 \\
\hline \multicolumn{4}{|c|}{ Kategori } & Cukup \\
\hline
\end{tabular}

Tabel II. Persentase Kuisioner Berdasarkan Indikator Tanda dan Gejala Dysmenorrhea

\begin{tabular}{|c|c|c|c|c|}
\hline \multirow{2}{*}{ No. } & \multirow{2}{*}{ Pernyataan } & \multicolumn{2}{|c|}{ Jawaban berdasarkan Kunci $(n=84)$} & \multirow{2}{*}{$\begin{array}{c}\text { Persentase } \\
\text { Jawaban Benar (\%) }\end{array}$} \\
\hline & & Benar & Salah & \\
\hline 3 & $\begin{array}{l}\text { Gejala dysmenorrhea diantaranya adalah rasa sakit yang datang } \\
\text { secara tidak teratur, menusuk dan kram di bagian bawah } \\
\text { perut yang menyebar kebagian belakang, kaki, pangkal paha } \\
\text { dan vulva (bagian luar } \\
\text { alat kelamin wanita). }\end{array}$ & 80 & 4 & 95,24 \\
\hline 4 & $\begin{array}{l}\text { Dysmenorrhea biasanya disertai rasa mual, pusing, bahkan } \\
\text { muntah. }\end{array}$ & 19 & 65 & 22,62 \\
\hline & $\begin{array}{ll}\text { Rata-rata persentase } \\
\end{array}$ & & & 58,93 \\
\hline & Kategori & & & Cukup \\
\hline
\end{tabular}

Tabel III. Persentase Kuisioner Berdasarkan Indikator Penyebab Dysmenorrhea

\begin{tabular}{|c|c|c|c|c|}
\hline \multirow{2}{*}{ No. } & \multirow{2}{*}{ Pernyataan } & \multicolumn{2}{|c|}{ Jawaban berdasarkan Kunci $(n=84)$} & \multirow{2}{*}{$\begin{array}{c}\text { Persentase } \\
\text { Jawaban Benar (\%) }\end{array}$} \\
\hline & & Benar & Salah & \\
\hline 5 & $\begin{array}{l}\text { Faktor lain seperti anemia dan penyakit menahun juga dapat } \\
\text { mempengaruhi timbulnya dysmenorrhea. }\end{array}$ & 46 & 38 & 54,76 \\
\hline 6 & $\begin{array}{l}\text { Dysmenorrhea disebabkan oleh siklus menstruasi yang tidak } \\
\text { teratur. }\end{array}$ & 61 & 23 & 72,62 \\
\hline & $\begin{array}{ll}\text { Rata-rata persentase } \\
\end{array}$ & & & 63,69 \\
\hline & Kategori & & & Cukup \\
\hline
\end{tabular}

Tabel IV. Persentase Kuisioner Berdasarkan Indikator Cara Penanganan dan Pencegahan Dysmenorrhea

\begin{tabular}{|c|c|c|c|c|}
\hline \multirow{2}{*}{ No. } & \multirow{2}{*}{ Pernyataan } & \multicolumn{2}{|c|}{ Jawaban berdasarkan Kunci $(n=84)$} & \multirow{2}{*}{$\begin{array}{c}\text { Persentase } \\
\text { Jawaban Benar (\%) }\end{array}$} \\
\hline & & Benar & Salah & \\
\hline \multirow[t]{2}{*}{7} & Dysmenorrhea dapat diatasi dengan meminum obat anti & 69 & 15 & 82,14 \\
\hline & nyeri. & 53 & 31 & 63,10 \\
\hline \multirow[t]{2}{*}{8} & Berolahraga dengan teratur dapat mengurangi/mengatasi & & & \\
\hline & gejala dysmenorrhea. & 65 & 19 & 77,38 \\
\hline \multirow[t]{2}{*}{9} & Kompres hangat dapat mengurangi/mengatasi gejala & & & \\
\hline & dysmenorrhea. & 44 & 40 & 52,38 \\
\hline \multirow[t]{3}{*}{10} & $\begin{array}{l}\text { Obat anti nyeri seperti Paracetamol atau Ibuprofen } \\
\text { merupakan obat yang dapat digunakan pada saat terjadinya } \\
\text { dysmenorrhea. }\end{array}$ & & & \\
\hline & Rata-rata persentase & & & 68,75 \\
\hline & Kategori & & & Cukup \\
\hline
\end{tabular}

Tabel V. Persentase Kuisioner Secara Keseluruhan

\begin{tabular}{|c|c|c|c|c|}
\hline \multirow{2}{*}{ No. } & \multirow{2}{*}{ Pernyataan } & \multicolumn{2}{|c|}{ Jawaban berdasarkan Kunci $(n=84)$} & \multirow{2}{*}{$\begin{array}{c}\text { Persentase } \\
\text { Jawaban Benar (\%) }\end{array}$} \\
\hline & & Benar & Salah & \\
\hline I & Dysmenorrhea merupakan rasa nyeri yang timbul ketika & 76 & 8 & 90,48 \\
\hline & menstruasi. & 47 & 37 & 55,95 \\
\hline 2 & Dysmenorrhea harus ditangani oleh dokter. & 80 & 4 & 95,24 \\
\hline 3 & $\begin{array}{l}\text { Gejala dysmenorrhea diantaranya adalah rasa sakit yang datang } \\
\text { secara tidak teratur, menusuk dan kramdibagian bawah perut }\end{array}$ & & & \\
\hline
\end{tabular}




\begin{tabular}{|c|c|c|c|c|}
\hline & yang menyebar kebagian belakang, kaki, pangkal paha dan vulva & 19 & 65 & 22,62 \\
\hline & (bagian luar alat kelamin wanita). & 46 & 38 & 54,76 \\
\hline \multirow[t]{2}{*}{4} & Dysmenorrhea biasanya disertai rasa mual, pusing, bahkan & & & \\
\hline & muntah. & 61 & 23 & 72,62 \\
\hline \multirow[t]{2}{*}{5} & Faktor lain seperti anemia dan penyakit menahun juga dapat & 69 & 15 & 82,14 \\
\hline & mempengaruhi timbulnya dysmenorrhea. & 53 & 31 & 63,10 \\
\hline \multirow[t]{2}{*}{6} & Dysmenorrhea disebabkan oleh siklus menstruasi yang tidak & & & \\
\hline & teratur. & 65 & 19 & 77,38 \\
\hline 7 & Dysmenorrhea dapat diatasi dengan meminum obat anti nyeri. & 44 & 40 & 52,38 \\
\hline 8 & $\begin{array}{l}\text { Berolahraga dengan teratur dapat mengurangi/mengatasi gejala } \\
\text { dysmenorrhea. }\end{array}$ & & & \\
\hline 9 & $\begin{array}{l}\text { Kompres hangat dapat mengurangi/mengatasi gejala } \\
\text { dysmenorrhea. }\end{array}$ & & & \\
\hline \multirow[t]{3}{*}{10} & $\begin{array}{l}\text { Obat anti nyeri seperti Paracetamol atau lbuprofen } \\
\text { merupakan obat yang dapat digunakan pada saat terjadinya } \\
\text { dysmenorrhea. }\end{array}$ & & & \\
\hline & Rata-rata persentase & & & 66,67 \\
\hline & Kategori & & & Cukup Mengetahui \\
\hline
\end{tabular}

Berdasarkan hasil keseluruhan penelitian tanpa pembagian indikator maka didapatkan hasil persentase $66,67 \%$ Termasuk dalam kategori cukup mengetahui, hasil penelitian ini dapat dijadikan sebagai dasar tenaga kesehatan setempat untuk melakukan penyuluhan kesehatan terutama tentang dysminorrhea untuk meningkatkan pengetahuan siswi tentang alat reproduksi sejak dini.

\section{KESIMPULAN}

Tingkat pengetahuan siswi SMA Muhammadiyah Palangka Raya Tahun ajaran 2018/2019 tentang dysmenorrhea termasuk dalam kategori cukup mengetahui dengan persentase $66,67 \%$. Saran untuk penelitian selanjutnya adalah melakukan penyuluhan kepada siswi SMA Muhammadiyah, kemudian di ukur kembali tingkat pengetahuannya dan juga melakukan penelitian yang sama pada siswi SMP untuk dibandingkan tingkat pengetahuannya tentang dysmenorrhea dengan siswi SMA.

\section{UCAPAN TERIMA KASIH}

Ucapan terimakasih kepada Universitas Muhammadiyah Palangkaraya atas pemberian dana dalam skema Hibah Penelitian Kajian Perempuan dan Anak melalui Lembaga Penelitian dan Pengabdian Masyarakat.

\section{DAFTAR PUSTAKA}

Abidin. 2014. Nyeri Haid pada Remaja. Jakarta: Rineka Cipta.
Anugraeni, S.D. 2017. Gambaran Penanganan Nyeri Dismenorea pada Siswi SMP Muhammadiyah di Kebumen. Skripsi, Sekolah Tinggi Ilmu Kesehatan Muhammadiyah Gombong.

Diyan, Indriyani. 20I3. Keperawatan Maternitas pada Area Perawatan Antenatal. Yogyakarta: Graha Ilmu.

Helvina, Emma. 2016. Efektivitas Pemberian Minuman Sari Kunyit Putih terhadap Penurunan Nyeri Haid Disminore Primer pada Siswi Kelas XI SMKN 3 Banjarmasin. Dinamika Kesehatan Vol 7 (I).

Nafiroh dan Indrawati. 2013. Gambaran Pengetahuan Remaja tentang Dismenore pada Siswa Putri di MTSNU Mranggen Kabupaten Demak. JIK 4: I5766.

Proverawati, A \& Siti Misaroh. 2009. Menarche Menstruasi Penuh Makna. Yogyakarta: Nuha medika.

Rahmawati, Tatik. 2016. Hubungan Tingkat Pengetahuan Dismenorea Mahasiswi Pendidikan Biologi UIN Walisongo Semarang terhadap Sikap mengatasi Dismenorea Primer. Skripsi, Universitas Islam Negeri Walisongo Semarang.

Rakhshaee, Z. 2014. A Cross Sectional Study of Primary Dysmenorrhea among Student at a University. Prevalence, Impact and of Associated Symptomps. Anuual Research and Review in Biology. 4 (18): 2815 22.

Reeder, Martin dan Koniak-Griffin. 2013. Keperawatan Maternitas Kesehatan Wanita, Bayi \& Keluarga, Edisi $8 \mathrm{Vol}$. Jakarta: EGC.

Risnomarta, S.D., Arnelis dan Ernawati. 2015. Hubungan OAINS pada Pengobatan Dismenorea dengan Kejadian Dispepsia pada Mahasiswi Fakultas Kedokteran Universitas Andalas, Jurnal Kesehatan Andalas 4 (2);4I5-420. 
Sibaragiang, E., E. Juliane Rismalinda dan Siti Nurzannah. 2010. Metodologi Penelitian untuk mahasiswi Diploma Kesehatan. Jakarta: Trans Info Media.

Yunitasari, Riski. 2017. Karakteristik dan Tingkat Stres Siswi dengan kejadian Dismenore Primer di SMPN3 Sragi Pekalongan. Thesis, Universitas Muhammadiyah Semarang. 